\title{
Magnetic Properties and Remanent Magnetization of Stony Meteorites
}

\author{
N. Sugiura* \\ Geophysical Institute, University of Tokyo, Tokyo, Japan
}

(Received March 7, 1977; Revised July 27, 1977)

\begin{abstract}
Hysteresis parameters and remanence properties of 22 stony meteorites were measured. Coercive force varies systematically in the sequence $\mathrm{E} \rightarrow \mathrm{H} \rightarrow$ $\mathrm{L} \rightarrow \mathrm{LL} \rightarrow \mathrm{C}$ chondrites. The change of natural remanent magnetization (NRM) stability follows the same sequence. Intensity of NRM is proportional to ferromagnetic mineral contents in meteorites. The ratio NRM/saturation magnetization is unrelated to the chemical class. Stability of NRM against alternating field demagnetization was compared to anhysteretic remanence (ARM) induced in a low field. The NRM in four meteorites is as stable as the ARM, and chemical remanence (CRM) or thermoremanence (TRM) origin of the NRM is inferred. NRM in eight meteorites is less stable than ARM. Stability and/or intensity of NRM was compared with that of isothermal remanence (IRM) and viscous remanence (VRM) and partial thermoremanence (pTRM). Artificial IRM and terrestrial VRM origin for NRM is ruled out; pTRM origin (acquired in the temperature range $20<T<200-300^{\circ} \mathrm{C}$ and in a field $0.5 \leq h \leq 2 \mathrm{Oe}$ ) of NRM in some meteorites seems likely, since such pTRM exhibits almost identical behavior with NRM.
\end{abstract}

\section{Introduction}

Banerjee and Hargraves (1972), Brecher (1972), Butler (1972), and Brecher and ARrhenius (1974) recently established that magnetic records of the extraterrestrial origin are preserved in most carbonaceous (C) chondrites. Thermoremanent magnetization (TRM), partial thermoremanent magnetization (pTRM), chemical remanent magnetization (CRM) and depositional remanent magnetization (DRM) origins of the natural remanent magnetization (NRM) in C chondrites have been proposed (BANerJeE and Hargraves, 1972; Brecher, 1972; Butler, 1972).

In spite of extensive studies on ordinary chondrites, it is not clear whether they have preserved magnetic records of extraterrestrial origin, mainly because NRMs in ordinary chondrites are much less stable than in C chondrites (STACEY

* Present address: Department of Geology, Erindale College, University of Toronto, Mississauga, Ont., Canada, L5L 1 C6. 
etal., 1961; WeAving, 1962; GUSKova, 1963, 1976; BreCHER and RANGANAYAKI, 1975). Although NRMs in ordinary chondrites were generally interpreted as TRM (or thermochemical remanence, TCRM) acquired during cooling through Curie (or transition) temperature (STACEY et al., 1961; WEAving, 1962; Guskova and Pochtarev, 1967), TRMs produced in laboratory are frequentry more stable than the NRMs (StaCey et al., 1961; BReCher and RANGANAYAKI, 1975).

To gain insight on the origin of NRMs in meteorites, (1) we measured the hysteresis parameters and examined NRM properties based on theose parameters, and (2) induced anhysteretic remanent magnetization (ARM), isothermal remanent magnetization (IRM), viscous remanent magnetization (VRM), and partial thermoremanence in the samples, and compared them with NRM intensity and/or stability against alternating field (AF) demagnetization.

Most samples studied here are Yamato meteorites collected on the bare-ice area near the Yamoto Mountains in Antarctica (Yoshida et al., 1971; SHIRAISHI et al., 1976). Magnetic properties of some of them were previously published (Nagata at al., 1975, 1976; Nagata and Sugiura, 1976).

2. Hysteresis Parameters

Hysteresis parameters (saturation magnetization, $J_{s}$; saturation remanence,

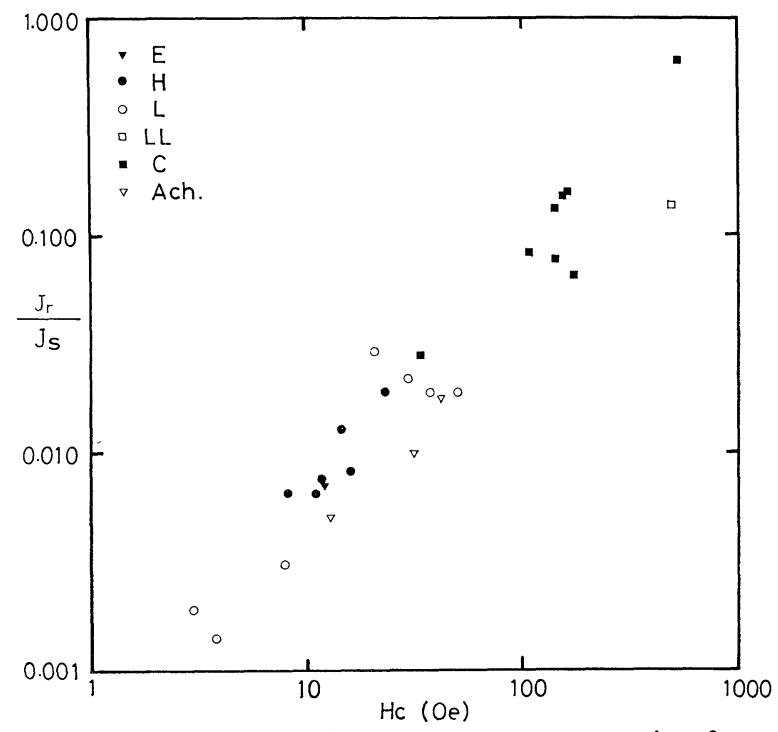

Fig. 1. Normalized saturation remanence vs. coercive force plot. $C$ chondrites and an LL chondrite are magnetically harder than $\mathrm{L}, \mathrm{H}, \mathrm{E}$ chondrites. L chondrites show more variety in their magnetic hardness than $\mathrm{H}$ chondrites. Some data of $\mathrm{C}$ chondrites are taken from BRECHER and ARRHENIUS (1974). 
$J_{r}$; and coercive force, $H_{c}$ ) were measured on a Princeton vibration magnetometer (sensitivity $10^{-2} \mathrm{emu}$ ). Measurements are summarized in Table 1 . Due to small sample size $(\leq 30 \mathrm{mg})$ and to relatively large magnetic minerals $(\leq 500 \mu)$, the absolute values of extensive variables $\left(J_{s}, J_{r}\right)$ in ordinary chondrites may contain a fluctuation of about $30 \%$.

In Fig. $1, J_{r} / J_{s}$ is plotted against $H_{c}$. These parameters are connected by $J_{r} / J_{s} \sim X_{0} \cdot H$ ( $X_{0}$ is initial susceptibility) and are the indexes of the magnetic hardness. It is apparent that $\mathrm{C}$ and LL chondrites are magnetically harder than $\mathrm{E}, \mathrm{H}$, and $\mathrm{L}$ chondrites. Hence, the relatively stable NRMs in $\mathrm{C}$ and LL chondrites (Brecher and Arrhenius, 1974; Brecher and Ranganayaki, 1975) are interpreted as due to high coercivity of constituent magnetic minerals, regardless the other conditions such as acquisition process of NRM. Variation of coercive force among various meteorites is partly due to the difference in the grain size of constituent magnetic minerals and partly due to the relative amount of plessite in the case of ordinary chondrites. $C$ chondrites contain fine grained

Table 1. Hysteresis parameters of meteorites.

\begin{tabular}{|c|c|c|c|c|c|}
\hline Sample & Type & $\begin{array}{c}J_{\boldsymbol{s}} \\
(\mathrm{emu} / \mathrm{g})\end{array}$ & $\begin{array}{c}J_{r} \\
(\mathrm{emu} / \mathrm{g})\end{array}$ & $\begin{array}{c}H_{c} \\
(\mathbf{O e})\end{array}$ & Reference \\
\hline Yamato-a & E 3 & 48.0 & $3.5 \mathrm{E}-1$ & 12 & 2 \\
\hline Seminole & $\mathrm{H} 4$ & 35.1 & $2.63 E-1$ & 16.1 & 1 \\
\hline Kesen & $\mathrm{H} 4$ & 34.4 & $2.28 \mathrm{E}-1$ & 8.1 & 1 \\
\hline Yamato-73-01 & $\mathrm{H} 4$ & 20.4 & $1.45 \mathrm{E}-1$ & 11.8 & 1 \\
\hline Yamato-74-371 & H5 & 39.1 & $3.03 \mathrm{E}-1$ & 13.4 & 1 \\
\hline Yamato-74-647 & $\mathrm{H} 5$ & 29.8 & $3.65 \mathrm{E}-1$ & 14.5 & 1 \\
\hline Yamato-d & $\mathrm{H} 6$ & 32.3 & $6.0 \mathrm{E}-1$ & 23 & 2 \\
\hline Yamato-74-191 & L 3 & 20.5 & $4.11 \mathrm{E}-1$ & 29.6 & 1 \\
\hline Fukutomi & L5 & 25.3 & $7.14 \mathrm{E}-1$ & 20.4 & 1 \\
\hline Yamato-73-04 & L 5 & 14.3 & $4.5 \mathrm{E}-2$ & 8.0 & 1 \\
\hline Yamato-73-12 & L 6 & 17.5 & $2.4 \mathrm{E}-2$ & 3.8 & 1 \\
\hline Yamato-74-362 & L 6 & 17.7 & $2.91 \mathrm{E}-1$ & 37.5 & 1 \\
\hline Dalgety Downs & $\mathrm{L}$ & 20.0 & $3.42 \mathrm{E}-1$ & 50.0 & 1 \\
\hline Mino & $\mathrm{L}$ & 11.0 & $2.1 \mathrm{E}-1$ & 3.0 & 1 \\
\hline St. Severin & L L 6 & 4.67 & $5.41 \mathrm{E}-1$ & 500 & 3 \\
\hline Leoville & $\mathrm{C} 3$ & 20.5 & $5.79 E-1$ & 33.8 & 1 \\
\hline Allende & $\mathrm{C} 3$ & 0.607 & $4.8 \mathrm{E}-2$ & 143 & 3 \\
\hline Yamato-c & $\mathrm{C} 3$ & 10.8 & $1.69 \mathrm{E} 00$ & 157 & 2 \\
\hline Karoonda & $\mathrm{C} 4$ & 7.84 & $1.22 \mathrm{E} 00$ & 155 & 3 \\
\hline Yamato-b & Ach. & 0.19 & $3.5 \mathrm{E}-3$ & 42 & 2 \\
\hline Yamato-73-07 & Ach. & 0.53 & $2.7 \mathrm{E}-3$ & 13 & 1 \\
\hline Yamato-74-013 & Ach. & 0.23 & $2.3 \mathrm{E}-3$ & 31.7 & 1 \\
\hline
\end{tabular}

Ref. 1: NAGAta and Sugiura, 1976. Some values are revised by multiple measurements.

Ref. 2: Nagata et al., 1975.

Ref. 3: This study. 


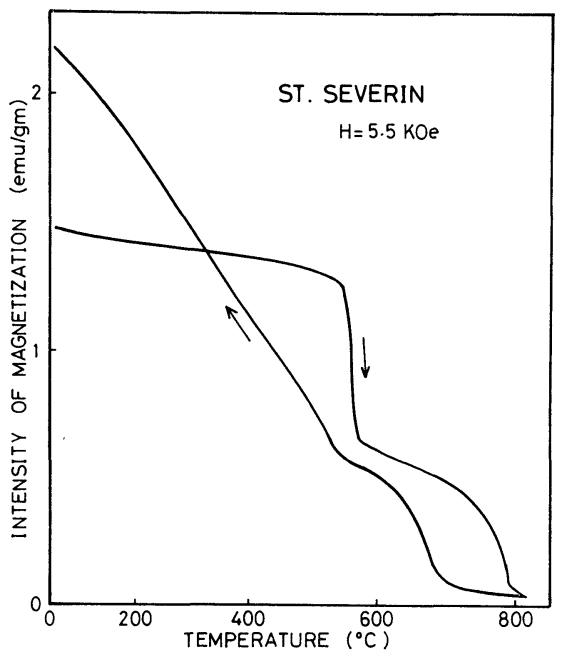

Fig. 2. Thermomagnetic curve of an LL chondrite (St. Severin). The sudden decrease of magnetization at $560^{\circ} \mathrm{C}$ in the heating cycle is due to the plessite $(\alpha+\gamma) \rightarrow$ taenite $(\gamma)$ transition.

magnetite $\left(\mathrm{Fe}_{3} \mathrm{O}_{4}\right)$, (JEDWEB, 1968; KERRIDGE, 1970), while ordinary chondrites contain mainly coarse grained kamacite. The large coercive force of the LL chondrites (St. Severin) is probably due to plessite. As shown by thermomagnetic analysis (Fig. 2), the main magnetic mineral in St. Severin whose transition temperature in the heating cycle is $560^{\circ} \mathrm{C}$, is plessite. (This transition is $\alpha+$ $\gamma \rightarrow \gamma$ transition of iron-nickel alloy. In the cooling cycle, decomposition of $\gamma$ does not occur due to fast cooling rate $\left(200^{\circ} \mathrm{C} / \mathrm{hr}\right)$ in this experiment. See also Lovering and PARRy, 1962.) The large coercive force of plessite is probably due to the microstructure which is similar to those observed in precipitationtype permanent magnets (ScotT, 1973). Since H and L chondrites also contain some amounts of plessite, the coercive force of these chondrites may also be a little affected by plessite.

\section{NRM Intensity and Stability}

Magnetic moments were measured on a Schonstedt SSM-1A spinner magnetometer (sensitivity $10^{-7} \mathrm{emu}$ ). Specimen shape was usually irregular because of sample scarcity. The fusion crust was removed before measurement. Sample weights ranged from 0.13 to $1.86 \mathrm{~g}$.

NRM intensities are summarized in Table 2 and shown in Fig. 3 as a histogram. When two or more measurements were made on the same meteorite, a 
weighted average is given. Figure 3 shows the NRM intensity in chondrites decreasing in the order $\mathrm{E} \rightarrow \mathrm{H} \rightarrow \mathrm{L} \rightarrow \mathrm{LL}$, as reported earlier (BRECHER and RANGANAYAKI, 1975; GoRshKov et al., 1972). This sequence is expected, since ferromagnetic mineral contents in meteorites decrease in the same sequence (see Table $\left.1, J_{s}\right)$. The small NRM intensity in achondrites and the varied NRM intensity in $\mathrm{C}$ chondrites can also be attributed to variations in ferromagnetic mineral contents, because normalized NRM intensity $\left(\mathrm{NRM} / J_{s}\right)$ is unrelated to the chemical class of meteorites (Fig. 3).

Stability of NRM in meteorites was studied by AF demagnetization using a 2 -axis tumbler system in a low field $(<500 \gamma)$ environment produced by 3 pairs of Helmholtz coils. AF demagnetization behavior of $\mathrm{C}$ chondrite is shown in Fig. 4. As was found by BanerJee and Hargraves (1972), LARson et al. (1973) and Brecher and Arrhenius (1974), C chondrites possess NRMs which are

Table 2. Remanence properties of meteorites.

\begin{tabular}{|c|c|c|c|c|c|c|c|}
\hline Sample & $\begin{array}{l}\text { NRM } \\
(\mathrm{emu} / \mathrm{g})\end{array}$ & $\begin{array}{l}H_{1 / e} \\
(\mathrm{Oe})\end{array}$ & $\begin{array}{c}h \\
(\mathrm{Oe})\end{array}$ & $\begin{array}{l}H_{1 / e}^{\prime} \\
(\mathrm{Oe})\end{array}$ & $\left(\frac{\mathrm{emu}}{\mathrm{g} \cdot \mathrm{Oe}}\right)$ & $\left(\begin{array}{c}S_{d} \\
\left(\frac{\mathrm{emu} / \mathrm{g}}{\mathrm{Oe} \cdot \log (\mathrm{sec})}\right)\end{array}\right.$ & Reference \\
\hline Yamato-a & $1.33 \mathrm{E}-2$ & 15 & 9.3 & 3.1 & $4.8 \mathrm{E}-5$ & $1.1 \mathrm{E}-5$ & 2 \\
\hline Seminole & $5.78 \mathrm{E}-3$ & 8 & 12 & 2.0 & $1.0 \mathrm{E}-4$ & $<2.7 \mathrm{E}-7$ & 1 \\
\hline Kesen & $7.05 \mathrm{E}-3$ & 3 & 5.6 & 1.5 & $2.2 \mathrm{E}-4$ & & 3 \\
\hline Yamato-73-01 & $1.77 \mathrm{E}-3$ & 10 & 2.3 & 0.9 & $1.4 \mathrm{E}-4$ & $1.2 \mathrm{E}-5$ & 3 \\
\hline Yamato-74-371 & $1.44 \mathrm{E}-3$ & 10 & 2.9 & 0.9 & $1.2 \mathrm{E}-4$ & $<2.6 \mathrm{E}-6$ & 3 \\
\hline Yamato-74-647 & $9.49 \mathrm{E}-4$ & & 1.7 & 0.9 & $8.9 E-5$ & $<3.8 \mathrm{E}-7$ & 3 \\
\hline Yamato-d & $5.67 \mathrm{E}-4$ & 58 & 3.1 & 1.6 & $5.2 \mathrm{E}-5$ & & 2 \\
\hline Yamato-74-191 & $1.53 \mathrm{E}-4$ & 235 & 3.3 & 1.0 & $1.1 \mathrm{E}-5$ & $1.1 \mathrm{E}-5$ & 3 \\
\hline Fukutomi & $1.47 \mathrm{E}-4$ & 5 & 8 & 1.8 & $7.4 \mathrm{E}-6$ & $9.4 \mathrm{E}-7$ & 1 \\
\hline Yamato-73-04 & $5.15 \mathrm{E}-4$ & 8 & 5.0 & 1.4 & $1.9 \mathrm{E}-5$ & $6.0 \mathrm{E}-6$ & 3 \\
\hline Yamato-73-12 & $7.66 E-4$ & 16 & 10.8 & 1.4 & $6.0 \mathrm{E}-6$ & & 3 \\
\hline Yamato-74-362 & $1.08 \mathrm{E}-3$ & 5 & 3.7 & 1.0 & $4.0 \mathrm{E}-5$ & $6.9 \mathrm{E}-6$ & 3 \\
\hline Dalgety Downs & $2.51 \mathrm{E}-3$ & 18 & 16 & 3.1 & $3.6 \mathrm{E}-5$ & $2.8 \mathrm{E}-6$ & 1 \\
\hline Mino & $1.59 \mathrm{E}-4$ & & & & & & 3 \\
\hline St. Severin & $7.36 \mathrm{E}-5$ & 1,000 & & & $3.5 \mathrm{E}-6$ & $1.4 \mathrm{E}-5$ & 3 \\
\hline Leoville & $4.36 \mathrm{E}-3$ & 30 & 12.1 & 3.8 & $2.8 \mathrm{E}-5$ & $3.0 \mathrm{E}-5$ & 1 \\
\hline Allende & $2.67 \mathrm{E}-4$ & 800 & 46 & 12 & $2.0 \mathrm{E}-7$ & $3.1 \mathrm{E}-6$ & 3 \\
\hline Yamato-c & $2.07 E-3$ & 160 & 34 & 13 & $1.6 \mathrm{E}-7$ & $8.8 \mathrm{E}-6$ & 2 \\
\hline Karoonda & $2.68 \mathrm{E}-4$ & 80 & 9 & 5 & $3.4 \mathrm{E}-6$ & $7.4 E-6$ & 3 \\
\hline Yamato-b & $1.54 \mathrm{E}-5$ & 340 & 26.5 & 18.4 & $2.0 \mathrm{E}-8$ & & 2 \\
\hline Yamato-73-07 & $4.89 \mathrm{E}-4$ & 112 & 10.5 & 5.0 & & & 4 \\
\hline Yamato-74-013 & $3.01 \mathrm{E}-6$ & 350 & 13.2 & 15.7 & $2.7 \mathrm{E}-8$ & $2.3 \mathrm{E}-7$ & 3 \\
\hline
\end{tabular}

Ref. 1: Nagata and Sugiura, 1977.

Ref. 2: NAGAta et al., 1975.

Ref. 3: This study.

Ref. 4: NAgAta et al., 1976.

Some of the values of Refs. 1, 2, and 4 are revised by multiple measurements. 
stable in both intensity and direction during AF demagnetization. My results for Allende and Leoville are consistent with previous results (BANERJEE and Hargraves, 1972; Butler, 1972; Larson et al., 1973; Brecher and Arrhenius, 1974), while the NRM in Karoonda is more stable in intensity and direction than reported by Brecher and Arrhenius (1974). Such variation of NRM properties in a meteorite may result from varying amounts of contaminating
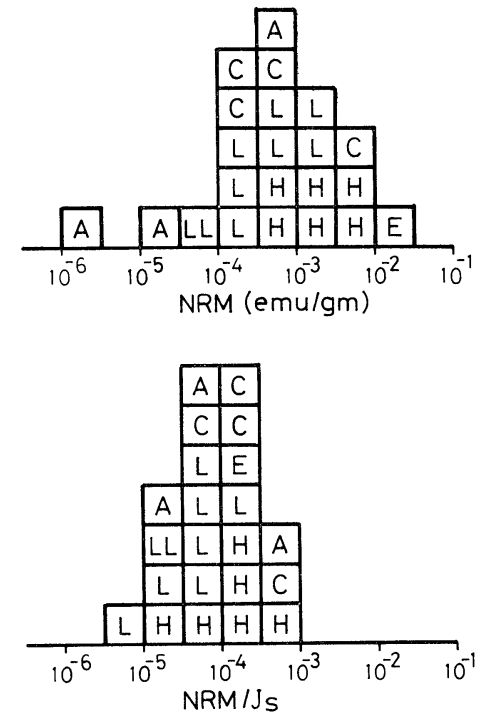

Fig. 3. Histograms of NRM intensity (top) and the normalized intensity of NRM (bottom) in various meteorites. The letters $\mathrm{E}, \mathrm{H}, \mathrm{L}, \mathrm{LL}, \mathrm{C}$ and $\mathrm{A}$ represent enstatite, bronzite, hypersthene, amphoterite, carbonaceous chondrites, and achondrite, respectively.

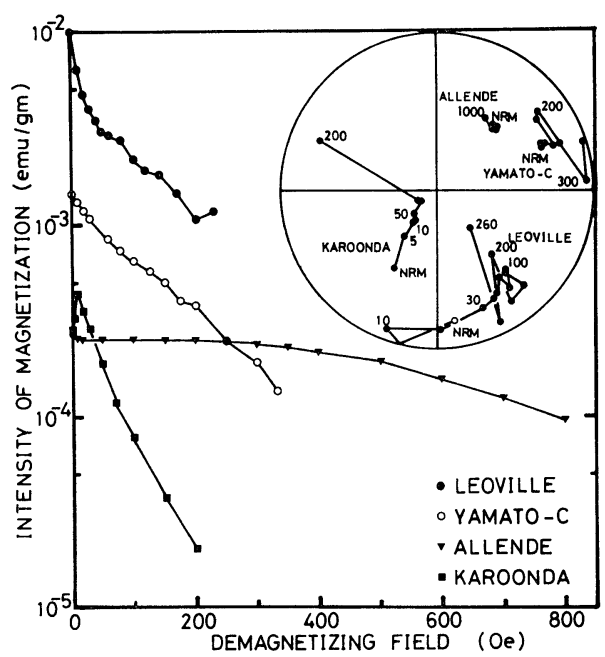

Fig. 4. Intensity and directional plot of AF demagnetization of $\mathrm{C}$ chondrites. 
IRM acquired after the meteorite fall, perhaps in museum or laboratory and/or may be due to local inhomogeneities. To reduce these undesirable effects, NRM intensity is demagnetized by $10 \mathrm{Oe} \mathrm{AF}$ and normalized to the saturation remanence $\left(\mathrm{NRM}_{10} / J_{r}\right)$ and used in the following discussion. In Fig. 5, $\mathrm{NRM}_{10} / J_{r}$ for $\mathrm{C}$ chondrites is plotted against bulk coercive force. $\mathrm{C}$ chondrites with similar

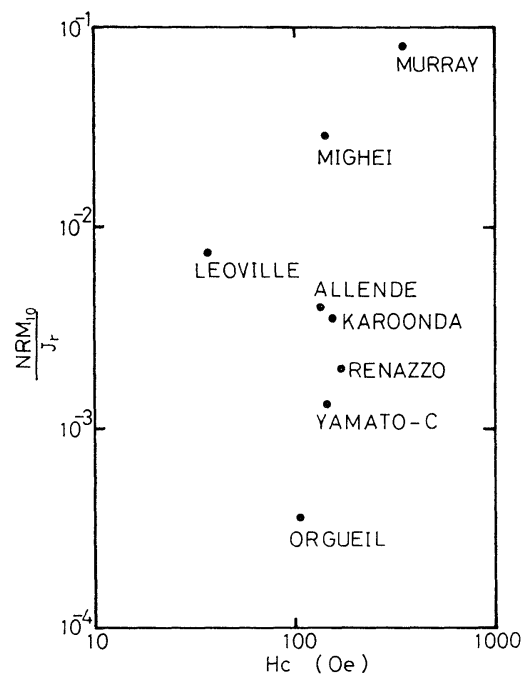

Fig. 5. Normalized NMR intensity and coercive force of $\mathrm{C}$ chondrites. The data of Murray, Mighei, Rennazzo, and Orgueil are taken from Brecher and ArRhenius (1974), where the data of NRM cleaned by low temperature cycles (which is nearly identical with or a little smaller than $\mathrm{NRM}_{10}$ ) were given.

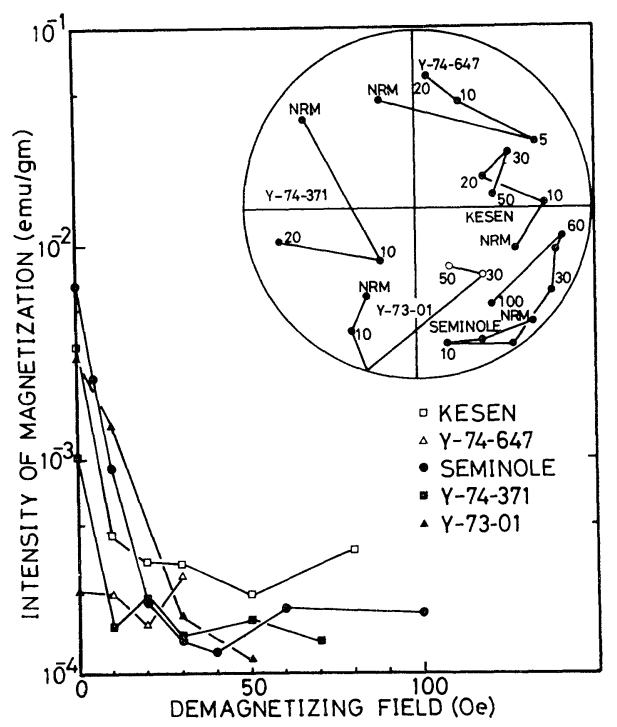

Fig. 6. Intensity and directional plot of AF demagnetization of $\mathrm{H}$ chondrites. 
coercive force exhibit $\mathrm{NRM}_{10} / J_{r}$ values which differ by two orders of magnitude, which suggests the NRM acquisition process might not be the same for various C chondrites.

AF demagnetization behaviors of $\mathrm{E}, \mathrm{H}, \mathrm{L}$, and LL chondrites are shown in Figs. 6-8. Most of the present samples of ordinary chondrites possess soft remanences demagnetized by alternating field of $<100 \mathrm{Oe}$.

Figure 6 illustrates that NRM in $\mathrm{H}$ chondrites is practically demagnetized by AF demagnetization to 20 Oe. Seminole has remanence with stable direction up to $100 \mathrm{Oe}$. The other $\mathrm{H}$ chondrites show no stable remanence in contrast to previous studies (Guskova, 1963; LARson et al., 1973; Brecher and RANGANAYAKI, 1975). It is possible that a more stable component in our samples might be concealed by noisy soft remanences. The undemagnetizable remanence of $1.5 \times 10^{-4} \mathrm{emu} / \mathrm{g}$ is the noise level for $\mathrm{H}$ chondrites by our system.

The NRMs in most $L$ chondrites are, as in $H$ chondrites, very unstable against AF demagnetization. A few are relatively stable and show monotonic decrease of the intensity down to $5 \times 10^{-5} \mathrm{emu} / \mathrm{g}$ (Fig. 7). Among L chondrites, Yamato-74-191 has the most stable remanence, which is directionally stable up to 250 Oe. For Yamato-73-04, the remance direction does not change much up to 100 Oe. The NRM direction in Dalgety Downs and Yamato-74-362 drifts gradually during AF demagnetization, indicating two components with different directions and stabilities.

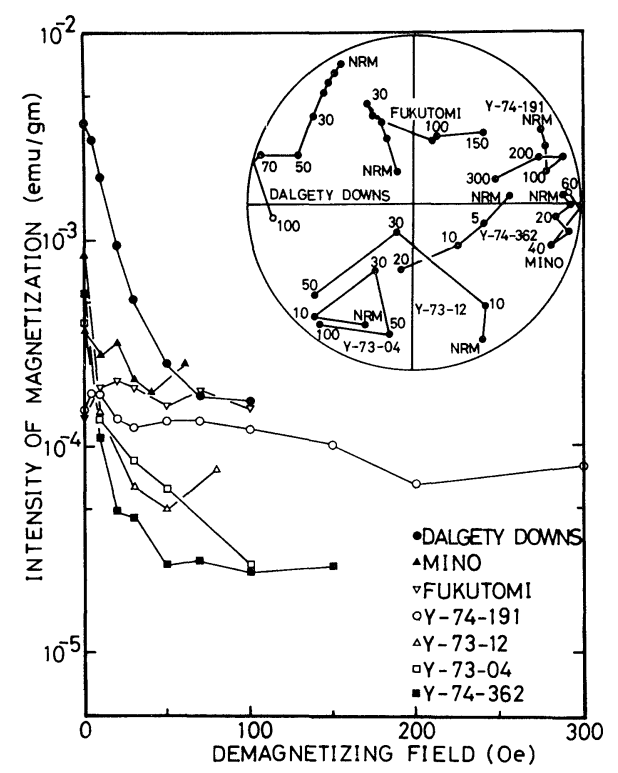

Fig. 7. Intensity and directional plot of AF demagnetization of $\mathrm{L}$ chondrites. 
NRM in the LL chondrite, St. Severin (Fig. 8) is extremely stable in intensity, but direction shifts gradually at high fields. The NRM intensity in Yamato-a, E chondrite (Fig. 8) is seven times larger than that of another piece of Yamato-a (NAGATA et al., 1975), but AF demagnetization behavior, i.e., rapid decrease of intensity with fairly constant direction, is similar. Therefore, the difference in NRM intensity may be due to sample inhomogeneity.

The present study confirms that NRM stability against AF demagnetization increases in the sequence $\mathrm{E} \rightarrow \mathrm{H} \rightarrow \mathrm{L} \rightarrow \mathrm{LL}$ chondrites (BRECHER and RANGANAYAKI, 1975). BRECHER and RANGANAYAKI (1975) suggested that the microstructure of metal phases may explain the trend of NRM stability. Plessite, the major magnetic phase of St. Severin, is responsible for the extreme stability of the NRM. But the coercive force of plessite (See Table 1, $H_{c}$ of St. Severin) is expected to be much larger than the median destructive field of NRMs in $\mathrm{E}, \mathrm{H}$, and $\mathrm{L}$ chondrites. Hence, instead of plessite, slight change in the kamacite grain size may be responsible for the stability trend among $\mathrm{E}, \mathrm{H}$, and $\mathrm{L}$ chondrites. Especially, the stability of NRM in Yamato-74-191 is due to fine kamacite grains. Composite troillite-kamacite grains are observed by optical microscope in Yamato74-191, and metal particle sizes range from a few $\mu$ to $<1 \mu$.

AF demagnetization behavior of achondrites are also shown in Fig. 8 . In general, NRM in achondrites is more stable than in $\mathrm{E}, \mathrm{H}$, and $\mathrm{L}$ chondrites, which may be due to the smaller metallic iron grains in achondrites compared

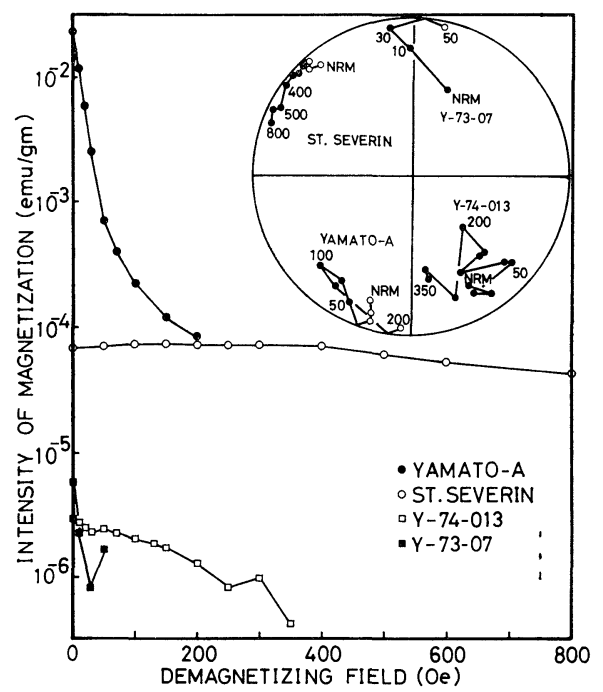

Fig. 8. Intensity and directional plot of AF demagnetization of an LL chondrite, an E chondrite and two achondrites. 
to the larger kamacite grains in chondrites. The difference in NRM stability between Yamato-04-013 and Yamato-73-07 is also due to the difference in grain size of metallic iron grains. Yamato-74-013, a diogenite, contains fine metallic iron grains, while Yamato-73-07, a howardite with eucritic clasts, contains larger metallic grains. The former has more stable remanence than the latter (Fig. 8).

\section{ARM of Meteorites}

That NRMs in most $\mathrm{E}, \mathrm{H}$, and $\mathrm{L}$ chondrites are unstable against AF demagnetization does not necessarily mean that their NRMs are paleomagnetically meaningless. Because of the relatively small coercive forces, even TRMs might be unstable. To compare the stability of TRM with NRM, STACEY et al. (1961) and BRecher and RANGANAYAKI (1975) imparted artificial TRM to various chondrites and found that TRMs are generally more stable than NRMs against thermal or AF demagnetization.

However, as established by BRECHER and RANGANAYAKI (1975), most chondrites are either chemically or metallurgically altered by heating to $800^{\circ} \mathrm{C}$. Figure 9 shows how AF demagnetization behavior of the $J_{r}$ was changed after heating to $800^{\circ} \mathrm{C}$ in mixed $\mathrm{CO}_{2}-\mathrm{H}_{2}$ (or $\mathrm{N}_{2}-\mathrm{H}_{2}$ ) gas atmosphere. (The equipment was described by KONO and TANAKA (1977)). The softening of the $J_{r}$ of ordinary chondrites is noteworthy. The softening may be caused by metallurgical change (plessite $\rightarrow$ taenite), because the coercive force of St. Severin, which contains abundant plessite, was notably reduced by the heating. Further, ARMs before and after heating are not identical in their coercivity spectrum (Fig. 10). In such cases, it is meaningless to compare the stability of NRM and TRM in detail (Allen, 1970).

Here, instead of TRM, ARM was compared with NRM in both intensity and AF demagnetization behavior. Previous work indicates that the properties of ARM are very similar to TRM induced by the same direct field. In paticular, RIMBERT (1959) showed that ARM and TRM have comparable stabilities against

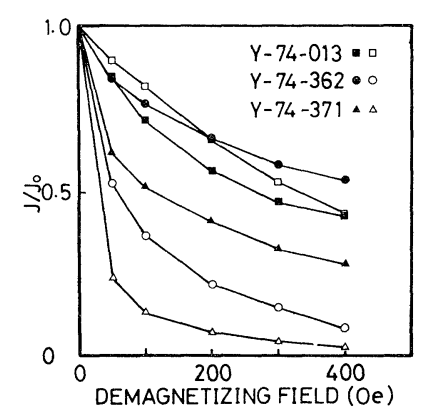

Fig. 9. Normalized AF demagnetization curve of the saturation remanence before (solid symbol) and after (open symbol) heating to $800^{\circ} \mathrm{C}$. 


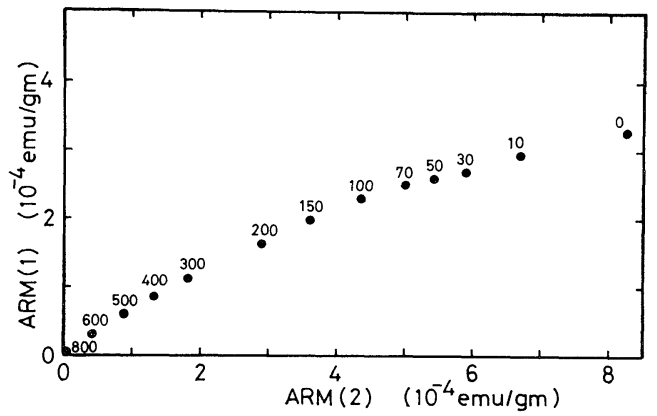

Fig. 10. Comparison of the coercive force spectra of the ARMs of the LL chondrite (St. Severin) before $(\operatorname{ARM}(1))$ and after $(\operatorname{ARM}(2))$ heating to $800^{\circ} \mathrm{C}$.

AF and thermal demagnetization and that ARM intensity is linearly proportional to a weak inducing field. Subsequent studies observed that ARM obeys the additivity law for partial ARMs (PAtton and Fitch, 1962; Dunlop and West, 1969). Johnson et al. (1975) demonstrated that ARM substitutes for TRM in applying the Lowrie-Fuller test (Lowrie and Fuller, 1971). Levi and MERrill (1976) found ARM and TRM to be similar in stability to AF demagnetization, temperature cycles in zero field to below magnetite's isotropic point near $130 \mathrm{~K}$, and to spontaneous decay in zero field. Similarity of stability against AF demagnetization of ARM and TRM in metallic iron grains also has been confirmed by STEPhenson and Collinson (1974).

Hence, it is reasonable to compare NRM with ARM to see whether NRM in meteorites is of TRM or (CRM) origin. (Since CRM is as stable as TRM, we cannot distinguish CRM from TRM by their coercivity spectrum (KoBAYASHI, 1959)). ARM was imparted by using solenoid coils. The direct field was applied parallel to the axis of the alternating field. The direct field intensity was $1.8 \mathrm{Oe}$, nearly the maximum at which the intensity of ARM is proportional to the intensity of the direct field (e.g., Banerjee and Mellema, 1974; Levi and Merrill, 1976). The maximum alternating field in our system is $800 \mathrm{Oe}$. The current through the DC coil is supplied by a constant current source, which is isolated from the alternating current induced by the alternating field, by a filter circuit.

To compare the coercivity spectrum of NRM with ARM, the NRM intensity at each demagnetizing stage is plotted against the ARM intensity at the same stage. If NRM is of TRM origin, a straight line should result. In Fig. 11, coercivity spectra of NRM and ARM are compared. Of 15 meteorites studied, only Allende, St. Severin, Yamato-74-013 and Yamato-74-191 showed a straight line portion. Due to noise, some deviation from linearity is seen in the latter two cases. The convexity at low fields may be due to partial spontaneous decay 


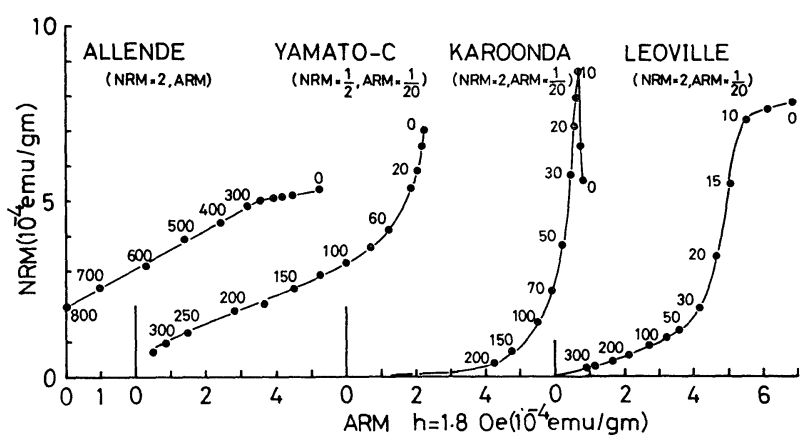

(a)

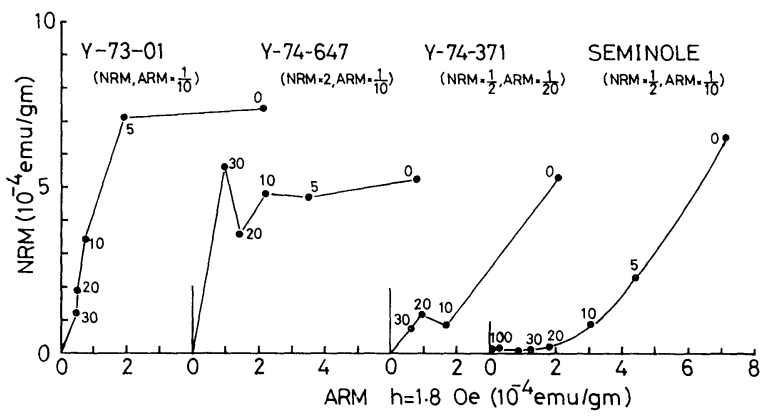

(b)

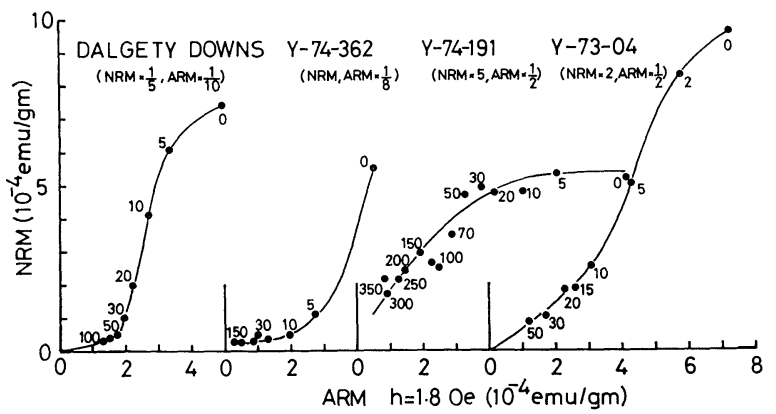

(c)

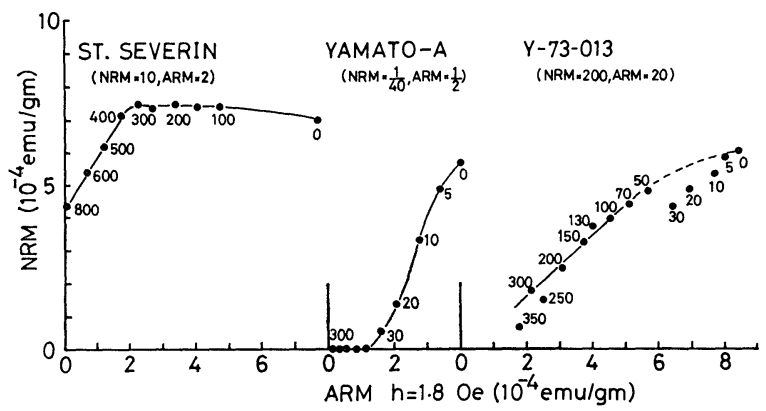

Fig. 11. Comparison of the coercive force spectra of the NRM and the ARM (direct field is $1.8 \mathrm{Oe}$ ). The numbers adjacent to the points indicate values of the peak alternating field. The intensity of magnetization is modified by the factor shown in the parentheses. 
of NRM. Therefore, these four meteorites may possess TRMs (or equally stable CRMs); e.g., for Allende, a carbonaceous chondrite, supposedly never heated above its Curie temperature $\left(620^{\circ} \mathrm{C}\right.$; BANERJEe and HARgRAVEs, 1972; ButLer, 1972) after its consolidation, the NRM can not be of TRM origin. Judging from its magnetic mineralogy (composite sulfied-metal grains; BANERJEE and HARgRaves, 1972), CRM origin of the NRM in Allende is most likely. Most of the NRM in St. Severin is probably carried by plessite. Since the exsolution of $\alpha$ phase iron-nickel alloy in plessite is presumed to have occurred at temperatures much less than its Curie temperature, the NRM in St. Severin also may be of CRM origin.

Since it is probable that fine metallic grains, probably produced by a reheating event, carry the NRM in Yamato-74-013 and Yamato-74-191, these NRMs are considered of TRM origin.

As shown in Fig. 11, the coercivity spectra of the NRM and the ARM in Yamato-74-371 are similar. But, judging from the unstable directional behavior of NRM against AF demagnetization (Fig. 6), we are not confident that the NRM is a TRM. Similarly, no reliable conclusion can be derived for Yamato74-647 and Yamato-73-01.

The other meteorites (Yamato-c, Karoonda, Leoville, Seminole, Dalgety Downs, Yamato-74-362, Yamato-73-04, and Yamato-a) exhibit concave NRMARM plots, indicating that remanences of higher coercivities are lacking in NRM compared with ARM. Therefore, the soft NRM in most chondrites (particularly in ordinary chondrites) reflects not only the magnetic softness of the constituent magnetic minerals but also the the acquisition mechanisms of the NRM. Mechanisms producing rather soft remanences such as IRM, VRM, SRM (shock remanent magnetization) and pTRM etc. may account for the NRMARM plot of these chondrites and are examined below.

\section{IRM of Meteorites}

In meteorites whose NRM stability is considerably less than that of ARM, IRM acquired subsequent to the meteorite fall must be examined. Parameters which characterize IRM are, $b$ : IRM acquisition rate defined by $b=\operatorname{IRM} / H^{2}$ ( $H$ is small external direct field), $h$ : the direct field imparting IRM (with intensity equal to the NRM intensity), and $H_{1 / e}^{\prime}$ : the alternating field needed to reduce IRM (acquired by the field $h$ ) to $1 / e$ of its initial value.

Measurements of these parameters are summarized in Table 2. In Fig. 12, $\mathrm{NRM} / J_{s}$ is plotted against $b / J_{s}$. A positive correlation is seen among the ordinary chondrites, and $h$ ranges from 1.7 to 16 Oe. Guskova (1976) obtained similar values of $h, 1.0<h<7.0$, for ordinary chondrites. The value of $h$ for $\mathrm{C}$ and $\mathrm{E}$ 
chondrites and achondrites ranges from 9 to 46 Oe. Direct fields of 10 Oe are often encountered in the laboratory, but meteoritic NRMs are more stable than IRMs. As shown in Fig. 13, $H_{1 / e}^{\prime}$ is usually much smaller than $H_{1 / e}$ (the alternating field needed to reduce NRM to $1 / e$ of its initial value, summarized in Table 2). Conversely, to impart an IRM with similar stability to NRM, a field of more than a few tens of Oe is required and IRM intensity becomes much larger than that of NRM. As shown later, spontaneous decay of IRM does not effectively reduce IRM intensity. Hence, artificial IRM origin of NRM is not feasible.

There is still further evidence against artificial IRM origin of NRMs in meteorites. Low temperature cycling is useful to clean the spurious soft component of NRM carried by multidomain magnetite (OzIMA et al., 1964). For remanences carried by magnetite, low temperature cleaning is interpreted as due to cooling through the isotropic point of magnetocrystalline anisotropy, where coercivity is considerably reduced and domain walls move to attain the state of minimum energy (demagnetized state). Unlike magnetite, iron-nickel alloy is not expected to exhibit an isotropic points of magnetocrystalline anisotropy between room temperature and liquid nitrogen temperature. Nevertheless,

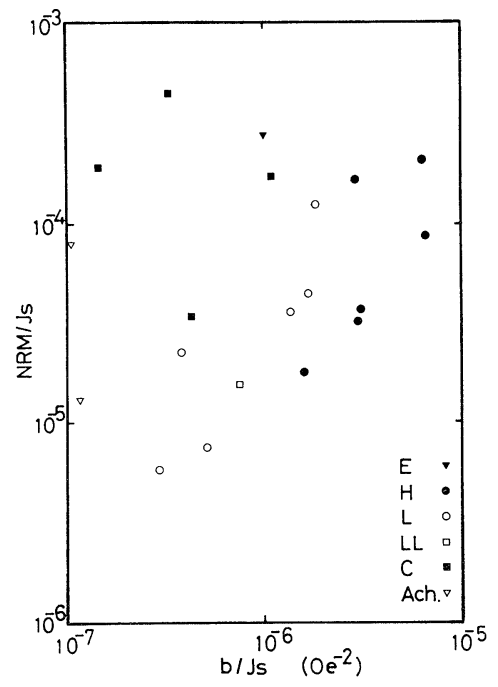

Fig. 12

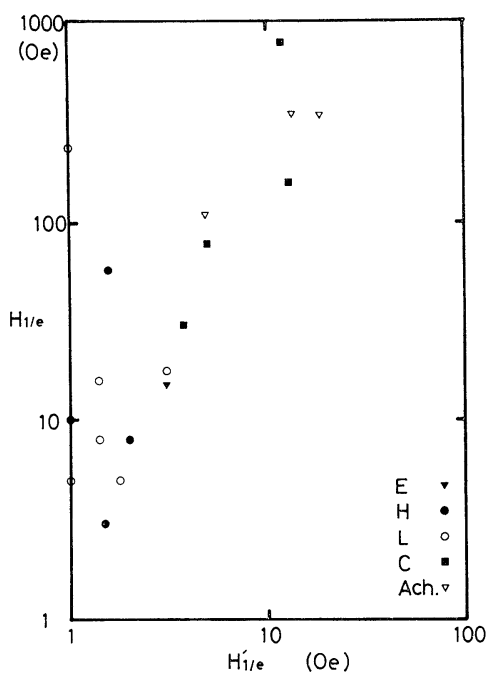

Fig. 13

Fig. 12. Normalized NRM against IRM acquisition coefficient plot. Positive correlation of these values can be recognized among $L$ and $H$ chondrites. The chondrites with most unstable NRM are situated at lower right.

Fig. 13. Comparison of the stability of the NRM and the IRM. $H_{1 / e}$ and $H_{1 / e}^{\prime}$ are the fields to reduce the intensity to $1 / e$ of its initial value of the NRM and the IRM, respectively. 
Table 3. Low temperature cycling.

\begin{tabular}{|c|c|c|c|}
\hline & $\frac{\text { NRM }^{*}}{\text { NRM }}$ & $\frac{\text { IRM* }^{*}}{\text { IRM }}$ & $\frac{\mathrm{ARM}^{*}}{\mathrm{ARM}}$ \\
\hline Yamato-74-371 & 0.88 & 0.11 & 0.76 \\
\hline Yamato-74-647 & 0.82 & 0.07 & 0.59 \\
\hline Yamato-74-191 & 1.04 & 0.10 & 0.87 \\
\hline Yamato-74-362 & 0.71 & 0.18 & 0.97 \\
\hline Allende & 0.98 & 0.59 & 0.71 \\
\hline Karoonda & 0.66 & 0.38 & 0.60 \\
\hline Yamato-74-013 & 1.03 & 0.67 & 0.97 \\
\hline
\end{tabular}

the remanences in lunar samples were reduced by low temperature cycling, and iron-nickel alloy is certainly responsible for the remanences in the lunar samples (NAGAta et al., 1971; DunN and Fuller, 1972; Brecher et al., 1974).

NRM, IRM with the same intensity as NRM, and ARM (direct field $=1.8$ Oe, alternating field $800 \mathrm{Oe}$ ) were subjected to low temperature cycling in a Permalloy shield case $(<200 \gamma)$. The ratio of remanence before and after low temperature cycling is summarized in Table 3. IRM is more effectively reduced by the low temperature cycling than ARM and low temperature cycling is more effective on samples composed of coarse grains (Yamato-74-371, 647, 191, and 362) than on meteorites composed of fine grains (Allende, Yamato-74-013). $\mathrm{NRM}$ in meteorites is much more stable than IRM against low temperature cycling. In particular, NRMs in meteorites where the remanence is carried by iron-nickel alloys are hardly reduced by the low temperature cycling. Therefore, in spite of instability against AF demagnetization, we conclude that the NRMs in most meteorites are not of artificial IRM origin.

\section{VRM of Meteorites}

It is not known when the Yamato meteorites fell. Therefore, it is important to know whether they can acquire VRMs in the earth's field during residence in the glacier. It is also important to know how much NRM in meteorites was reduced by spontaneous decay during flight through non-magnetic interplanetary space.

VRM was imparted by applying the same field $(h)$ used to impart IRM, for one day and its spontaneous decay was measured by a spinner magnetometer. The VRM decayed linearly with $\log t$ in the time range $10^{1.5}<t<10^{5} \mathrm{sec}$, from which decay coefficient $S_{d}=\mathrm{dVRM} / \mathrm{d} \log t$ was determined. The results are summarized in Table 2. From the theory of VRM (e.g., Dunlop, 1973) and as shown for several meteorites by Guskova (1963), most ordinary chondrites, which are largely composed of multidomain grains, acquire relatively small 
VRM. In particular, VRM in $\mathrm{H}$ chondrites is below the detection limit, and the upper limit of VRM component calculated from the detection limit is shown in the table. (Yamato-73-01 is an exception, probably due to the presence of maghemite as a weathering product.)

In those meteorites which acquire relatively large VRM, fine iron-nickel grains were observed by optical microscope. For example, Yamato-74-013 (achondrite), one of the most viscous samples, contains large amounts of fine metallic grains which exsolved from silicates. Yamato-74-191, another of the most viscous meteorites, contains composite iron-nickel and sulfide grains (whose grain size ranges from a few $\mu$ to $<1 \mu$ ), probably produced by a reheating event. Therefore, we infer that meteorites which acquire considerable VRM have experienced reheating and rapid cooling, analogous to the lunar regolith process, although there are exceptions such as $\mathrm{C}$ chondrites which contain fine magnetic grains of primordial origin.

Assuming that the acquisition coefficient of VRM is equal to the decay coefficient and that the acquisition of VRM continues to a sufficiently long time as $\mathrm{VRM}=S_{d} \log t, \mathrm{VRM}$ intensity in various meteorites, acquisitive in the earth's field are compared with $\mathrm{NRM}_{10}$ (Fig. 14). Even for the most viscous meteorites, more than a million years are required to produce VRM with intensity equal to $\mathrm{NRM}_{10}$. The time during which Yamato meteorites resided in the glacier is unknown, but even the Brunhes epoch is shorter than a million years. Hence

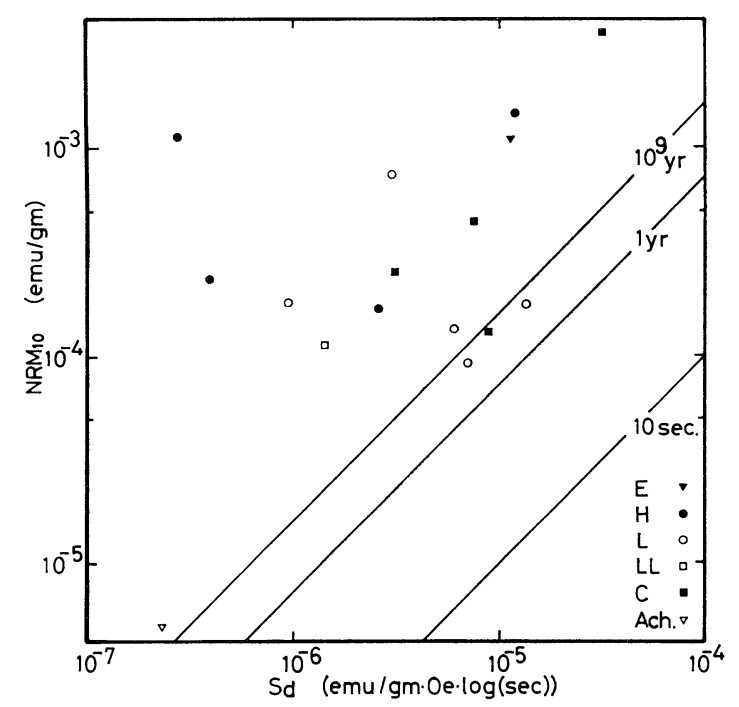

Fig. 14. NRM (demagnetized by $10 \mathrm{Oe} A F$ ) plotted against the decay coefficient of VRM. Solid lines indicate the VRM acquirable in the respective periods. 
the hypothesis that the observed NRM in Yamato meteorites may be due to VRM acquired in the geomagnetic field after these meteorites had fallen on Antarctica may be ruled out.

From cosmic ray exposure ages, meteorites are presumed to have been in non-magnetic interplanetary space at least for a few million years. Thus, we interpret some of the convex NRM-ARM plot (Fig. 11, e.g., Allende, Yamato74-191) at low field as spontaneous partial decay of the NRM.

\section{7. pTRM of Meteorites}

Partial TRMs were imparted to Allende, Karoonda, Yamato-73-04, and Dalgety Downs between room temperature and successively higher temperatures in a magnetic field of $0.5-4.0 \mathrm{Oe}$. To minimize chemical changes during heating, experiments were carried out in purified $\mathrm{N}_{2}$ for Karoonda and in $\mathrm{N}_{2}+\mathrm{H}_{2}$ in other cases. To detect possible chemical changes, AF demagnetization behaviors of ARMs before and after heating were compared (SHAw, 1974). If the ARMs are not identical, the data of PTRM is useless. To examine the similarity between NRM and pTRM, AF demagnetization behaviors of both remanences were compared.

For Allende, pTRMs were imparted between room temperature and 120 and $150^{\circ} \mathrm{C}$. A slight change of AF demagnetization behavior, decrease of the high coercivity component of the ARM, was observed after heating to $120^{\circ} \mathrm{C}$. It became more pronounced after heating to $150^{\circ} \mathrm{C}$, and the data of $\mathrm{pTRM}_{20^{\circ} \mathrm{C}}^{150^{\circ} \mathrm{C}}$ was discarded. Although $\operatorname{pTRM}_{20^{\circ} \mathrm{C}}^{120^{\circ} \mathrm{C}}$ is considerably stable (Fig. 15), it is less stable than NRM. The chemical change, which occurred by heating to 120 $150^{\circ} \mathrm{C}$ is presumably the manifestation of the fact that the meteorite has never been heated to these temperatures. Hence, it is supposed that the NRM in Allende is not acquired as pTRM.

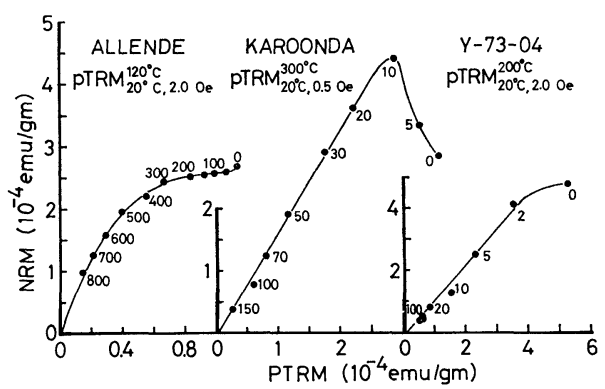

Fig. 15. NRM against pTRM plot of chondrites. The number adjacent to the points indicate values of the peak alternating field. 
For Karoonda, pTRMs were imparted between room temperature and 120 , 230 , and $300^{\circ} \mathrm{C}$. The ambient field intensity was chosen so that the intensity is similar to NRM. From monitoring ARM, no chemical change was observed by heating to $300^{\circ} \mathrm{C}$. The pTRM becomes gradually more stable with increase of the temperature used to impart the pTRM, and the pTRM ${ }_{20}^{300^{\circ} \mathrm{C}, 0.5(\mathrm{Ce})}$ is almost identical with the NRM with respect to both intensity and stability (Fig. 15).

For Yamato-73-04 and Daigety Downs, pTRMs were imparted between room temperature and 100,200 , and $300^{\circ} \mathrm{C}$. After heating $300^{\circ} \mathrm{C}, \mathrm{ARM}$ intensities were slightly larger than the original ARM, and PTRM becomes more stable than NRM. As shown in Fig. 15, the NRM-pTRM $M_{20^{\circ} \mathrm{C}, 2.0(\mathrm{O}) \text { e) }}^{20{ }^{\circ} \mathrm{C}}$ plot for Yamato-73-04 is almost linear and their intensities are similar. For Dalgety downs, similar result was obtained, although the linearity of the NRM-pTRM plot is worse than that for Yamato-73-04.

\section{Discussion and Conclusions}

Only four meteorites out of 15 studied in detail had linear NRM-ARM plots, and hence TRM or CRM origin of NRM was inferred. Eight exhibited concave NRM-ARM plots, indicating that remanence of higher coercivities is lacking in NRM compared with ARM. Artificial IRM or terrestrial VRM origin of NRM in these meteorites seems unlikely. But pTRM acquired between room temperature and $200-300^{\circ} \mathrm{C}$, in the field of $0.5-2.0 \mathrm{Oe}$, is almost identical to the NRM in some of these meteorites and is a likely mechanism of the NRM.

There are other possible origins of NRM in meteorites, such as SRM and DRM, not considered experimentally here. However, the possibility that NRMs in meteorites were acquired as SRMs by impact with the earth in the earth's magnetic field, can be evaluated following the argument of STACEY et al. (1961). From Eq. (4) in STACEY et al. (1961), the upper limit of SRM $/ J_{s}$ is $\sim 10^{-4}$. As shown in Fig. 3, about half of the present samples have values of $\mathrm{NRM} / J_{s}$ larger than $10^{-4}$. Since the properties of NRM in most chondrites seem to be unrelated to $\mathrm{NRM} / J_{s}$, and since it is supposed that all (small) meteorites impacted with the earth rather similarly, it seems that the upper limit value of $\mathrm{SRM} / J_{s}$ is not attained by the impact with the earth. On the other hand, intensive extraterrestrial shock is not readily eliminated as a source of NRM in certain meteorites, mainly due to the uncertainty of the shock pressure. If a shock pressure $\sim 50$ kbar and a field $\sim 0.5$ Oe are assumed, SRM may become as large as NRM, but in this case, SRM may become similar to pTRM (Cisowski et al., 1973). Further experiments are desirable on SRM of meteorites.

DRM origin of NRM in C chondrites has been considered (BANERJEE and 
Hargraves, 1972; BRECher, 1972). Since the stability of DRM is almost identical with the stability of the remanence in each magnetic particle (STACEY and BANERJEE, 1974), ARM-NRM(DRM) plot must be linear if each grain possesses pre-accretional remanence of TRM (or CRM) origin. Since the ARM-NRM plot of Karoonda, Yamato-c and Leoville is not linear, DRM origin of NRM is not likely for these meteorites. Since the ARM-NRM plot of Allende has a linear segment, DRM origin of NRM in Allende is not readily ruled out. The difficulty of DRM origin for Allende is that DRM is less efficient than the other mechanisms. For example, Opdyke et al. (1973) measured NRM(DRM) and ARM of a deep-sea core, and found that ARM is about ten times greater than DRM. Hence although there are many unknown factors, such as gravity and disturbance by impacts, which affect the intensity of extraterrestrial DRM, a field of $\sim 10$ Oe may be required to produce the NRM intensity in Allende.

Whether NRM in Yamato-74-371, Yamato-74-647, and Yamato-73-01 which possess the least stable remanence in the present samples is meaningful, is at present uncertain. The magnetic softness of the constituent magnetic minerals in these chondrites, which is shown by a large value of $b / J_{s}$ (Fig. 12), makes it difficult to obtain reliable results.

For the present meteorites, most of the NRMs seem to have been acquired as CRM (two meteorites), pTRM or SRM (eight meteorites) at rather low temperatures and total TRM (two meteorites) does not seem to be the major mechanism of the NRM in meteorites, contrary to the previous conclusions (STACEY et al., 1961; LARSON et al., 1973).

The author thanks Prof. T. Nagata for his continuous encouragement and for allowing the author to use many meteorite samples. The author thanks Prof. M. Ozima, Dr. M. Kono and Dr. Y. Hamano for their advice and useful discussions. He also thanks Dr. H. Mabuchi and Dr. S. Murayama who generously lent him valuable meteorites. This work was supported in part by a grant from National Institute of Polar Research.

\section{REFERENCES}

Allen, R.W., Investigations into a new method for finding ancient magnetic field intensities using anhysteretic properties of rocks, Ph. D. Thesis, University of Liverpool, 1970.

BANミRJEE, S.K. and R.B. HARGRAVES, Natural remanent magnetizations of carbonaceous chondrites and magnetic field in the early solar system, Earth Planet. Sci. Lett., 17, 110-119, 1972.

BanerJee, S.K. and J.P. Mellema, A new method for the determination of paleointensity from the ARM properties of rocks, Earth Planet. Sci. Lett., 23, 177-184, 1974.

BRECHER, A., Memory of early magnetic fields in carbonaceous chandrites, in On the Origin of the Solar System, Proc. CNRS Symp., pp. 260-273, 1972.

BRECHER, A. and G. ARrhenius, The paleomagnetic record in carbonaceous chondrites: Natural remanence and magnetic properties, J. Geophys. Res., 79, 2081-2106, 1974.

Brecher, A. and R.P. Ranganayaki, Paleomagnetic systematics of ordinary chondrites, Earth Planet. Sci. Lett., 25, 57-67, 1975. 
Brecher, A., W.H. Menke, and K.R. Morash, Comparative magnetic studies of some Apollo 17 rocks and soils and their implications, in Proc. 5th Lunar Sci. Conf., pp. 2795-2814, 1974.

Butler, R.F., Natural remanent magnetization and thermomagnetic properties of the Allende meteorite, Earth Planet. Sci. Lett., 17, 120-128, 1972.

Cisowski, C.S., M. Fuller, M.E. Rose, and P.J. WAsilewski, Magnetic effects of experimental shocking of lunar soil, in Proc. 4th Lunar Sci. Conf., pp. 3003-3017, 1973.

Dunlop, D.J., Theory of magnetic viscosity of lunar and terrestrial rocks, Rev. Geophys. Space Phys., 11, 855-901, 1973.

Dunlop, D.J. and C.F. WEST, An experimental evaluation of single domain theories, Rev. Geophys. Space Phys., 7, 709-757, 1969.

DunN, J.R. and M. Fuller, On the remanent magnetization of lunar samples with special reference to 10048, 55 and 14053, 48, in Proc. 3rd Lunar Sci. Conf., pp. 2363-2386, 1972.

Gorshkov, E.S., E.G. Guskova, and V.I. Pochtarev, Physical properties of meteorites, Mod. Geol., 3, 105-106, 1972.

Guskova, E.G., Investigation of natural remanent magnetization of stony meteorites, Geomag. Aeron., 3, 308-313, 1963.

Guskova, E.G., The Magnetic Properties of Meteorites, 147 pp., NASA TT F-792, 1976.

Guskova, E.G. and V.I. Pochtarev, Magnetic field of planets according to a study of the magnetic properties of meteorites, Geomag. Aeron., 7, 609-611, 1967.

Jedweb, J., Variations morphologiques de la magnétite des météorite carbonées d'Alais, Ivna et Orgueil, in Origin and Distribution of the Elements, edited by L.H. Ahren, 1178 pp., Pergamon Press, Oxford, 1968.

Johnson, H.P., W. Lowrie, and D.V. KENT, Stability of anhysteretic remanent magnetization in fine and coarse magnetite and maghemite particles, Geophys. J., 41, 1-10, 1975.

Kerridge, J.F., La magnétite de la météorite d'Orgueil vue au microscope électronique à balayage, Earth Planet. Sci. Lett., 9, 299-306, 1970.

KobAYASHI, K., Chemical remanent magnetization of ferromagnetic minerals and its application to rock magnetism, J. Geomag. Geoelectr., 10, 99-117, 1959.

Kono, M. and H. TANAKA, Influence of partial pressure of oxygen on thermoremanent magnetization of basalts, Phys. Earth Planet. Inter., 13, 276-288, 1977.

Larson, E.E., D.E. Watson, J.M. Herndon, and M.W. Rowe, Partial AF demagnetization studies of 40 meteorites, J. Geomag. Geoelectr., 25, 331-338, 1973.

Levi, S. and R.T. Merrill, A comparison of ARM and TRM in magnetite, Earth Planet. Sci. Lett., 32, 171-184, 1976.

Lovering, J.F. and L.G. PARry, Thermomagnetic analysis of co-existing nickel-iron metal phases in iron meteorites and the thermal histories of the meteorites, Geochim. Cosmochim. Acta, 26, 361--382, 1962.

Lowrie, W. and M. FULLER, On the alternating field demagnetization characteristics of multidomain thermoremanent magnetization in magnetite, J. Geophys. Res., 76, 6339-6349, 1971.

Nagata, T., R.M. Fisher, F.C. Schwerer, M.D. Fuller, and J.R. DunN, Magnetic properties and remanent magnetization of Apollo 12 lunar materials and Apollo 11 lunar microbreccia, in Proc. 2nd Lunar Sci. Conf., pp. 2461-2476, 1971.

Nagata, T. and N. Sugiura, Magnetic characteristics of some Yamato meteorites, magnetic classification of stone meteorites, Mem. Natl. Inst. Polar Res., Ser. C, No. 10, 30-58, 1976.

Nagata, T. and N. Sugiura, Paleomagnetic field intensity derived from meteorite magnetization, Phys. Earth Planet. Inter., 13, 373-379, 1977.

Nagata, T., N. Sugiura, and F.C. Schwerer, Notes on magnetic properties of the Yamato meteorites, Mem. Natl. Inst. Polar Res., Special Issue, No. 5, 91-110, 1975.

Nagata, T., N. Sugiura, and F.C. Schwerer, Magnetic properties of Yamato-73-04 and Yamato-73-07 meteorites, Mem. Natl. Inst. Polar Res., Ser. C, No. 10, 12-29, 1976. 
Opdyke, N.D., D.V. Kent, and W. Lowrie, Details of magnetic polarity transitions recorded in a high deposition rate deep-sea core, Earth Planet. Sci. Lett., 20, 315-324, 1973.

Ozima, M., M. Ozima, and T. NAGAta, Low temperature treatment as an effective means of 'magnetic cleaning' of natural remanent magnetization, J. Geomag. Geoelectr., 16, 37-40, 1964.

Patton, B.J. and J.L. Fitch, Anhysteretic remanent magnetization in small steady fields, $J$. Geophys. Res., 67, 307-311, 1962.

Rimbert, F., Contribution à l'étude de l'action de champs alternatifs sur les aimantation rémanentes des roches, Applications geophysiques, Rev. Inst. Fr. Pet., 14, 123-155, 1959.

Scotr, E.R.D., The nature of dark-etching rims in meteoritic taenite, Geochim. Cosmochim. Acta, 37, 2283-2294, 1973.

SHAw, J., A new method of determining the magnitude of the paleomagnetic field: Application to five historic lavas and five archaeological samples, Geophys. J., 39, 133-141, 1974.

Shiraishi, K., R. NARUSE, and K. KuSUnOKI, Collection of Yamato meteorites Antarctica, in December 1973, Antarc. Res., 55, 44-60, 1976.

Stacey, F.D. and S.K. BanerJee, The Physical Principles of Rock Magnetism, 195 pp., Elsevier, New York, 1974.

STACeY, F.D., J.F. Lovering, and L.G. PARRY, Thermomagnetic properties, natural magnetic moments and magnetic anisotropies of some chondritic meteorites, J. Geophys. Res., 66, 1523-1534, 1961.

Stephenson, A. and D.W. Collinson, Lunar magnetic field paleointensities determined by an anhysteretic remanents magnetization method, Earth Planet. Sci. Lett., 23, 220-228, 1974.

Weaving, B., The magnetic properties of Brewster meteorite, Geophys. J., 7, 203-211, 1962.

Yoshida, M., H. Ando, K. Omoto, R. Naruse, and Y. Agata, Discovery of meteorites near Yamato Mountains, East Antarctica, Antarc. Res., 39, 62-65, 1971. 